\title{
The Application of Self-Regulated Strategies to Blended Learning
}

\author{
Kuang-yun $\operatorname{Ting}^{1} \&$ Mie-sheng Chao ${ }^{2}$ \\ ${ }^{1}$ Department of Applied English, St. John's University, Taiwan \\ ${ }^{2}$ Department of English Laguage and Literature, Chinese Culture University, Taiwan \\ Correspondence: Kuang-yun Ting, Department of Applied English, St. John's University, Taiwan. E-mail: \\ sandrine@mail.sju.edu.tw
}

Received: April 8, 2013 Accepted: April 29, 2013 Online Published: June 3, 2013

doi:10.5539/elt.v6n7p26 URL: http://dx.doi.org/10.5539/elt.v6n7p26

\begin{abstract}
This study analyzes vocational college students' self-regulated strategies for blended learning. It investigates whether there are any differences in self-regulated learning strategies among students with gender and achievement variables. Twenty-two students at a vocational college in an EFL (English as a Foreign Language) context participated in the project; a structured questionnaire was used as the major research instrument and the TOEIC (Test of English for International Communication) English Test to categorize students' competence in English. In the four subcategories of self-regulated learning strategies, the results show that the students obtained their highest scores in metacognitive and the lowest in cognitive strategies. It was observed that: a) there was a correlation between the students' level of linguistic competence and their action control strategy; $b$ ) students with a high level of competence performed better than those with an intermediate one; c) gender was not reflected in any significant difference in any of the sub-categories but the statistic data revealed that male students had more confidence in cognitive and action control sub-categories than female students, this is potentially a field that needs further study.
\end{abstract}

Keywords: e-learning, self-regulated learning, Moodle

\section{Introduction}

As network technology has advanced - with breaking through the limits of space and time and adapting the learning characteristics of digital learning - it has brought new opportunities for teaching and learning. An online course management application, Moodle, has been designed to enable teachers to build and manage digital courses. Moodle, an abbreviation for "Modular Object Oriented Dynamic Learning Environment", is a free online open source learning management system. Teachers can upload course contents and manage their online classes. English teachers can also design ore practical or engaging activities to insert in a course with different techniques for teaching reading or writing. Bonk (2009) points out three benefits of using open learning sources. First, they allow institutions to offer courses which would be too costly otherwise; secondly, they make more linguistic and cultural sources available to individuals who would not otherwise be able to access them and thirdly, they create communities of like-minded educators who not only share programming talents and courses, but are interested in improving the human condition as well.

The rapid development and wide application of e-learning systems has led to many opportunities for self-learning but teachers and traditional classroom teaching are still needed by the majority of students and so more and more colleges employ "blended instruction" to manage teaching. Blended instruction, a combination of traditional classroom teaching and online learning methods is popular and more practical for both teachers and learners. In addition to retaining the advantages of classroom face-to-face interaction, online learning tools can extend the benefits of the course. Generally speaking, blended learning usually employs a wide variety of media and materials as well as different teaching methods and assessment tools (Sharma \& Barrett, 2007).

The term "blended learning" has become more and more prominent in second language classrooms (MacDonald, 2008 ) as it combines traditional learning with an Internet online application. It not only provides more choices in learning, but also brings many benefits, such as enhanced learning effectiveness, extended scope for learning, economy in time and costs, a faster supply of knowledge and information. Students are expected to be motivated by blended learning, and eventually, to realize their learning objectives. While learning can be influenced by many factors, many educators agree that self-regulated learning strategy plays a fairly important role (Ramdass 
\& Zimmerman, 2011). Accordingly, this project aims to analyze vocational college students' self-regulated learning strategies for blended instruction, and to help teachers and students find ways to improve and encourage efficient knowledge acquisition assisted by such methods in the context of higher education.

\section{Theoretical Foundations}

As learners choose the best approach for learning the material, they obtain their necessary skills and behave like their habits. These processes are called self-regulated learning strategies (Dweck \& Grant, 2008; Perry, 1998; Boekaerts \& Corno, 2005). Zimmerman (2000) regards self-regulation as thoughts, feelings and actions that are planned and adapted to the attainment of personal goals. Self-regulated learning is an important construct in education which consists of three general aspects of academic learning such as behavior, motivation and cognition (Zimmerman, 1998). Zimmerman (1989) specified three characteristics of self-regulated learning.

First, self-regulation of behavior includes the active control of the various resources for students' use, such as learning time, learner studying environment and other help available from their peers and faculty members (Pintrich, 2000). If self-regulation of behavior works well, it enables people to change their behavior. Accordingly, it is believed as the most important of these processes. Second, self-regulation of motivation and affect comprises controlling and changing motivational beliefs such as self-efficacy and goal orientation, in order that students can be fit for the demands of a course. In addition, students can learn how to control their emotions and affect (such as anxiety) in ways to promote their learning. Finally, self-regulation of cognition embraces the control of various cognitive strategies for learning, such as the use of deep processing strategies that lead to better learning and performance (Garcia \& Pintrich, 1994).

Educational psychologists tend to consider the ability to regulate one's own learning process as the key to successful learning in school and beyond (Cleary \& Zimmerman, 2004). Researchers have consequently redefined successful learning and designed powerful new learning environments in which the knowledge, skills, and attitudes associated with self-regulation can be acquired. Certain influential educational psychologists have proposed models and set up cross-sectional and longitudinal studies to produce theoretically relevant as well as pragmatic information about self-regulated learning (Kaplan, 2008). Self-regulated learning depends on learners' ability in the learning process to stimulate and maintain their own thoughts, actions and emotions, to achieve their aim (Nota, Soresi \& Zimmerman, 2004). In the process, learners set learning goals based on the specific characteristics of the tasks to be completed. In order to achieve assigned tasks, learners need to monitor, control, and adjust their faculties of cognition, action and emotion (Kreber et al., 2005). Being able to regulate one's own learning is viewed by educational psychologists as the key to successful learning in school and beyond. The imagery power of this construct is so strong that researchers have redefined successful learning and designed powerful online learning environments in which the knowledge, skills, and attitudes associated with self-regulation can be acquired.

The personal attributes of self-regulated learning are often described in terms of motivational beliefs and appropriate use of cognitive, metacognitive and action control strategies (Pintrich, 2004). Motivational beliefs have been defined as learners' inspiration, learning guidelines and choices (Lodewyk et al., 2009; Wolters \& Pintrich, 1998). Pintrich and De Groot (1990) establish a positive link between motivational beliefs and self-regulated learning and claim that all affective components influence academic performance. Cognitive components are regarded as regulatory strategies to help students monitor and control their own learning. Students who use such strategies are more cognitively engaged and acquire better understanding of the concept (Weinstein and Mayer, 1986). Metacognitive strategy refers to the ability to monitor and adjust the reasoning and cognitive processes such as learning, understanding and problem solving (Woolfolk, 2007). Action control strategy refers to the effort to protect one's aims from other competing tendencies (Kuhl, 1987). Because of the establishment of a digital teaching platform in recent years, students have more opportunities for interaction and practice; however, the design of the digital learning system needs careful attention to ensure that the self-learning process is optimised.

In spite of the availability of various learning management systems for self-learning, teachers and traditional classroom teaching are still needed by the majority of students. For this reason, blended learning, a combination of traditional classroom teaching and online learning methods is popular and more practical for both teachers and learners. In addition to retaining the advantages of classroom face-to-face interaction, online learning tools can extend the advantages of a given course. Generally speaking, blended learning usually employs a wide variety of media and materials, and different teaching methods and assessment tools as well Leakey \& Ranchoux (2006). Researchers (Stubbs, Martin \& Endlar, 2006) also support that blended learning not only provides more choices in learning, but also brings many benefits, such as enhancing learning effectiveness, extending learning scope for 
learning, economy in time and costs, a faster supply of knowledge and information. In this study, Moodle is the online learning tool used.

Moodle is a Course Management System (CMS) designed to help educators who want to create quality online courses. Other names, such as Learning Management System or Virtual Leaning Environment are also used to define the concepts of Moodle (Rice, 2011). The software is used all over the world by universities, schools, companies and independent teachers. Moodle, developed by Martin Dougimas, is an open source and completely free to use. The major concept applied to Moodle is that of social constructive pedagogy, which allows teachers and students to think and solve problems collaboratively, and hence, students can generate or develop new knowledge of their own (Stanford, 2009).

\section{Methodology}

The principal rationale of this study was to analyze vocational college students' self-regulated learning strategies to blended instruction. Specifically, the researcher investigates whether there are any differences related to gender and achievement in self-regulated learning strategies among students.

\subsection{Research Participants}

The participants in this study were 22 vocational college students in an EFL (English as a Foreign Language) context. Ten male students and twelve female students participated majored in Applied English in a four-year bachelor degree program. The reason to choose the students as the research participants was because their English levels were basically in the same level. The Test of English for International Communication (TOEIC) provided the criteria to assess students' English proficiency. The majority of the students did not get high scores but they were still at intermediate or lower-intermediate levels.

The TOEIC (Test of English for International Communication) scale is shown below.

Table 1. Comparison of CEF levels and scores for TOEIC and IELTS exams

\begin{tabular}{l|l|l|l|l|l|l}
\hline Level & \multicolumn{2}{|l|}{ elementary } & \multicolumn{2}{l|}{ intermediate } & \multicolumn{2}{l}{ advanced } \\
\hline $\begin{array}{l}\text { Common European Framework } \\
\text { CEF Levels }\end{array}$ & A1 & A2 & B1 & B2 & C1 & C2 \\
\hline TOEIC & Below 225 & 225 & 550 & 785 & 945 & $950+$ \\
\hline IELTS & 2.0 & 3.0 & 3.5 & 5.0 & 6.5 & $7+$ \\
\hline
\end{tabular}

The same level was very helpful not only to conduct classroom teaching but also to explore how the students with lower English proficiency apply self-regulated learning strategies to their language learning.

\subsection{Research Design}

The whole research period lasted for the semester, and blended instruction was employed as the teaching method. Students were asked to take part in face-to-face instruction and asynchronous online learning using the Moodle system. The course was constructed in 2010 combining school platform (Moodle) features, course configuration and content to develop the following structure. The 18-week course layout was based on a writing course syllabus which was intended to give students a basic understanding of writing structures and word usage. In addition to the regular teaching process, students had to read announcements and join peer discussion group periodically on the Moodle. At the end of the semester, each student was asked to fill in a self-regulated learning strategy questionnaire which was subsequently analyzed.

\subsection{Instruments}

The questionnaire used in this study was developed by Pintrich (2004) to analyze students' self-regulated learning strategies. The structure of the questionnaire was fourfold: motivation strategy, cognitive strategy, meta-cognitive strategy and action control strategy; each section contains twelve statements. Students were asked to indicate how valid each statement appeared to them. There were no right or wrong answers and they were invited to just answer as accurately as possible. The Likert five-point scale was used to analyze students' answers, with " 5 " representing "very true", and " 1 " representing "not at all true".

\section{Data Analysis}

Data analysis will be presented in descriptive statistics and inferential statistical format. To understand the target 
population, descriptive statistics were used to analyze the percentage of male and female students, and students' achievement levels, while a t-test and ANOVA were the basis for assessing whether there were differences in self-regulated learning strategies among students of varying demographic origins.

\subsection{Results}

The research results are based on descriptive data including the students' gender and achievement levels distribution and inferential statistical analyses are used to assess any differences in self-regulated learning strategies among students with different demographic variables. The results can be summarized as follows:

1. Gender: The target group consisted of $45.5 \%$ male students and $54.5 \%$ female students.

2. Achievement level: the three categories of a student's achievement level were: high, medium, and low. There were $22.7 \%$ students with high achievement, $50.0 \%$ with medium achievement, and $27.3 \%$ with low achievement. These results are shown in Figure 1.

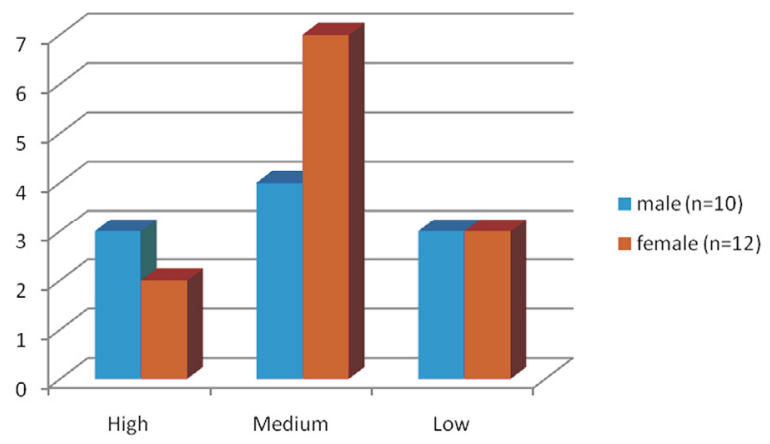

Figure 1. Gender and achievement level distribution

3. Self-regulated learning strategies and gender analysis: The mean of the four categories of self-regulated learning scores are listed in Table 2.

Table 2. Self-regulated learning strategies and gender analysis

\begin{tabular}{lllll}
\hline Category & $\begin{array}{l}\text { Mean of total } \\
\text { student in } \\
\text { category }\end{array}$ & $\begin{array}{l}\text { Mean of } \\
\text { male } \\
\text { students }\end{array}$ & $\begin{array}{l}\text { Mean of } \\
\text { female } \\
\text { students }\end{array}$ & Sig. of t-test \\
\hline $\begin{array}{l}\text { Motivation adjustment } \\
\text { strategies }\end{array}$ & 3.71 & 3.89 & 3.58 & .183 \\
\hline Cognitive strategies & 3.52 & 3.82 & 3.28 & .079 \\
\hline Meta-cognitive strategies & 3.74 & 3.98 & 3.55 & .148 \\
\hline $\begin{array}{l}\text { Action control } \\
\text { strategies }\end{array}$ & 3.48 & 3.76 & 3.25 & .079 \\
\hline
\end{tabular}

The mean of the motivation and meta-cognitive strategies is higher than that of the cognitive and action control strategies. Among the four categories, the mean of the meta-cognitive strategies is the highest, and the lowest that of the action control strategies. The correlation between students' gender and their self-regulated learning scores does not reveal any statistically significant difference in any of the categories. Although the t-test does not show a statistical significance above the .05 levels, the results show that male students had much higher scores in cognitive and action control strategies than female students ( 0.79 levels).

4. Self-regulated learning strategies and achievement analysis: To investigate if a students' achievement level made any differences in the self-regulated learning scores, ANOVA was used to see if there were any statistically significant differences in the four categories. The results showed that it was only in the action control category that statistical significance reached the .05 level (Table 3). Table 3 gives the statistical data and the results indicate that students with high achievement scores had better action control strategies than low achievement students. 
Table 3. Students' self-regulated learning strategies and achievement analysis

\begin{tabular}{|c|c|c|c|c|c|}
\hline Category & $\begin{array}{l}\text { Mean of total } \\
\text { student in } \\
\text { category }\end{array}$ & $\begin{array}{l}\text { Mean of high } \\
\text { score group }\end{array}$ & $\begin{array}{l}\text { Mean of medium } \\
\text { score group }\end{array}$ & $\begin{array}{l}\text { Mean of } \\
\text { low score } \\
\text { group }\end{array}$ & $\begin{array}{l}\text { Sig. of } \\
\text { ANOVA }\end{array}$ \\
\hline $\begin{array}{l}\text { Motivation } \\
\text { adjustment } \\
\text { strategies }\end{array}$ & 3.71 & 3.87 & 3.81 & 3.41 & .261 \\
\hline Cognitive strategies & 3.52 & 3.84 & 3.54 & 3.24 & .343 \\
\hline $\begin{array}{l}\text { Meta-cognitive } \\
\text { strategies }\end{array}$ & 3.74 & 3.63 & 3.74 & 3.44 & .454 \\
\hline $\begin{array}{l}\text { Action control } \\
\text { strategies }\end{array}$ & 3.48 & 3.85 & 3.58 & 2.99 & $.048 * *$ \\
\hline
\end{tabular}

\subsection{Discussion}

In the results, there are several findings worthy of notice. First, the average of each category is between 3.48 and 3.71, which explains the fact that these college students' self-regulated strategies in the blended instruction are quite good in general. As for the differences in the four categories of self-regulated learning, the average scores for motivation and meta-cognitive strategies are higher than those for cognitive and action control strategies, which suggest that the advantages of an e-learning environment are closed linked to design and the interaction to help students in the management of their studying and their self-motivation.

As for the relation between students' gender and self-regulated learning scores, there were no significant differences between self-regulated learning scores at the .05 levels but male students had much higher scores in cognitive and action control strategies than female students (.079 levels). This corresponds to the findings of Yukselturk and Bulut's (2009), which showed that there were not statistically significant mean differences among motivational beliefs, self-regulated learning variables and achievement in programming with respect to gender but stress arising from anxiety about the test could explain a significant amount of variance in female students' self-efficacy for learning and performance, and the value of a given task than their male counterparts' performance.

It is also important to notice that there is a positive correlation between achievement level and the action control strategies scores, revealing that students with high achievement scores have better action control strategies than low achievement students and supports the theoretical assumption proposed by Zimmerman (2000), who argued self-regulated learners were more intrinsically motivated, and hence could manage their learning, and engage in more meta- cognitive monitoring and control themselves better.

\section{Conclusions}

This study aimed to analyze vocational college students' self-regulated learning strategies with regard to blended instruction. Specifically, the researcher investigated whether there were any differences in self-regulated learning strategies among students with gender and achievement variables. The result showed that college students generally have good self-regulated learning strategies for blended instruction. However, there are learning achievement differences in self-regulated learning strategies. Students with high achievement scores had better action control strategies than low achievement students. On the other hand, the correlation between students' gender and self-regulated learning scores does not show any significant differences in the self-regulated learning scores, but the results do indicate that male students had much higher scores in cognitive and action control strategies than those of female students. More studies are required to test the possible impact of other factors on students' self-regulated learning scores, such as internet use or anxiety caused by the technology. Further studies are necessary to investigate how to improve the under-achievers to control their learning and improve their learning achievements in blended instruction.

\section{References}

Bonk, C. (2009). The World is Open: How Web technology is revolutionizing education. San Francisco: Jossey-Bass. http://dx.doi.org/10.1002/9781118269381

Boekaerts, M., \& Corno, L. (2005). Self-regulation in the classroom: A perspective on assessment and intervention. Applied Psychology, 54, 267-99. http://dx.doi.org/10.1111/j.1464-0597.2005.00205.x

Cleary, T., \& Zimmerman, B. (2004). Self-regulation empowerment program: A school-based program to 
enhance self-regulated and self-motivated cycles of student learning. Psychology in the Schools, 41(5), 537-550. http://dx.doi.org/10.1002/pits.10177

Dweck, C., \& Grant, H. (2008). Self-Theories, Goals and Meaning. In J. Shah, \& W. Gardner (Eds.), Handbook of Motivation Science. New York: The Guildford Press.

Garcia, T., \& Pintrich, P. R. (1994). Regulating motivation and cognition in the classroom: The role of self-schemas and self-regulatory strategies. In D. H. Schunk, \& B. J. Zimmerman (Eds.), Self-regulation of learning and performance: Issues and educational applications. Hillsdale, NJ: Lawrence Erlbaum Associates.

Kaplan, A. (2008). Clarifying Metacognition, Self-Regulation, and Self-Regulated Learning: What's the Purpose? Educational Psychology Review, 20, 477-484. http://dx.doi.org/10.1007/s10648-008-9087-2

Kreber, C., Castleden, H., Erfani, N., \& Wright, T. (2005). Self-regulated learning about university teaching: an exploratory study. Teaching in Higher Education, 10(1), $75-97$. http://dx.doi.org/10.1080/1356251052000305543

Kuhl, J. (1987). Action control: The maintenance of motivational states. In F. Halisch, \& J. Kuhl (Eds.), Motivation, Intention and Volition (pp. 279-291). Berlin: Springer.

Leakey, J., \& Ranchoux, A. (2006). BLINGUA. A blended language learning approach for CALL. Computer Assisted Language Learning, 19(4), 357-372. http://dx.doi.org/10.1080/09588220601043016

Lodewyk, K., Winne, P., \& Jamieson-Noel, D. (2009). Implications of task structure on self-regulated learning and achievement. Educational Psychology, 29(1), 1-25. http://dx.doi.org/10.1080/01443410802447023

MacDonald, J. (2008). Blended learning and online tutoring: Planning learner support and activity design (2nd ed.). Burlington: Gower Publishing Company.

Nota, L., Soresi, S., \& Zimmerman, B. (2004). Self-regulation and academic achievement and resilience: A longitudinal study. International Journal of Educational Research, 41(3), 198-215. http://dx.doi.org/10.1016/j.ijer.2005.07.001

Perry, N. E. (1998). Young children's self-regulated learning and contexts that support it. Journal of Educational Psychology, 90, 715-29. http://dx.doi.org/10.1037/0022-0663.90.4.715

Pintrich, P. (2004). A Conceptual Framework for Assessing Motivation and Self-Regulated Learning in College Students. Educational Psychology Review, 16(4), 385-407. http://dx.doi.org/10.1007/s10648-004-0006-x

Pintrich, P. (2000). The role of goal orientation in self-regulated learning. In J. Boekarts, P. Pintrich, \& M. Zeidner (Eds.), Handbook of Self-Regulation Burlington. MA: Elsevier Academic Press. http://dx.doi.org/10.1016/B978-012109890-2/50043-3

Pintrich, P., \& De Groot, E. (1990). Motivational and self-regulated learning components of classroom academic $\begin{array}{lllll}\text { performance. Journal of Educational } & \text { Psychology, }\end{array}$ http://dx.doi.org/10.1037/0022-0663.82.1.33

Ramdass, D., \& Zimmerman, B. (2011). Developing Self-Regulation Skills: The Important Role of Homework. Journal of Advanced Academics, 22(2), 194-218. http://dx.doi.org/10.1177/1932202X1102200202

Rice, W. (2011). Moodle 2.0 E-Learning Course Development. Birmingham: Packt Publishing.

Sharma, P., \& Barrett, B. (2007). Blended Learning: using technology in and beyond the language classroom. Oxford: Macmillan.

Stanford, J. (2009). Moodle 1.9 for Second Language Teaching. Birmingham: Packt Publishing.

Stubbs, M., Martin, I., \& Endlar, L. (2006). The structuration of blended learning: putting holistic design principles into practice. British Journal of Educational Technology, 37(2), 163-175. http://dx.doi.org/10.1111/j.1467-8535.2006.00530.x

Weinstein, C., \& Mayer, R. (1986). The teaching of learning strategies. In M. C. Wittrock (Ed.), Handbook of Research on Teaching (pp. 315-327). New York: Macmillan.

Wolters, C., \& Pintrich, P. (1998). Contextual differences in student motivation and self-regulated learning in mathematics, English, and social studies classrooms. Instructional Science, 26(1), 27-47. http://dx.doi.org/10.1023/A:1003035929216

Woolfolk, A. (2007). Educational psychology (10th ed.). Boston: Allyn \& Bacon. 
Yukselturk, E., \& Bulut, S. (2009). Gender Differences in Self-Regulated Online Learning Environment. Educational Technology \& Society, 12(3), 12-22.

Zimmerman, B. (1998). Academic studying and the development of personal skill: A self-regulatory perspective. Educational Psychologist, 33(2), 73-86. http://dx.doi.org/10.1207/s15326985ep3302\&3_3

Zimmerman, B. (2000). Attaining self-regulation. A social cognitive perspektive. In M. Boekaerts, P. R. Pintrich, \& M. Zeidner (Eds.), Handbook of self-regulation (pp. 13-39). San Diego, CA: Academic Press.

Zimmerman, B. J. (1989). A social cognitive view of self-regulated academic learning. Journal of Educational Psychology, 81, 329-339.

\section{Copyrights}

Copyright for this article is retained by the author(s), with first publication rights granted to the journal.

This is an open-access article distributed under the terms and conditions of the Creative Commons Attribution license (http://creativecommons.org/licenses/by/3.0/). 